\title{
Educação Ambiental: Práticas Pedagógicas Aplicadas no Consumo Diário
}

\author{
Educación Ambiental:Práticas pedagógicas aplicadas em El consumo
}

\author{
diário
}

Environmental Education: Practices Applied in Daily Consump

\author{
Cibele Stefanno Saldanha ${ }^{1}$ \\ Sarana Martins Leivas ${ }^{2}$ \\ Mauro Kumpfer Werlang ${ }^{3}$
}

\begin{abstract}
Resumo
O consumo é um tema transversal relevante a todas as disciplinas escolares e deve ser desenvolvido no sentido de abranger toda a totalidade de vida no cotidiano dos educandos. A geografia aborda questões do consumo em diferentes aspectos do espaço Geográfico frente ao mundo globalizado. Assim no que tange a vida cotidiana do cidadão requerem-se programas, ações e formas de apropriação dos bens de consumo na vida dos cidadãos. A problemática que envolve o consumo da cidade faz parte de um tema transversal no ensino escolar. O objetivo do trabalho é a aplicação atividades pedagógicas que favoreçam a construção de educandos críticos e conscientes sobre as formas de consumo no cotidiano de nossa sociedade nesse sentido voltado a Educação Ambiental e Popular, serão utilizados recursos didático pedagógicos e práticas-educativas sobre o estudo do consumo. $\mathrm{O}$ público alvo da pesquisa são os alunos da Escola Municipal de Ensino Fundamental Euclides da Cunha situada no bairro Carolina, cidade de Santa Maria, RS. Portanto, o processo de ensino-aprendizagem dos educandos e dos educadores no fazer pedagógico foi elaborado assiduamente permitindo a reflexão e a formação de cidadãos que vivem e constroem o cotidiano do seu lugar e de sua cidade. As temáticas propostas nesse projeto referentes à cidade, cidadania, consumo sustentável que estão sendo articuladas ao estudo do lugar/bairro e aos métodos que fundamentam as práticas adequadas à aprendizagens, atitudes e comportamentos educacionais em avaliação dos alunos, visto que os resultados das atividades foram satisfatórios, os objetivos do projeto foram alcançados com êxito.
\end{abstract}

Palavras-Chave: Cidadão; Conscientização; Ensino da Geografia; Sustentabilidade.

\section{Resumen}

El consumo es un tema transversal relevante a todas las disciplinas escolares y debe ser desarrollado en el sentido de abarcar toda la totalidad de la vida en el cotidiano de los educandos. La geografía aborda cuestiones del consumo en diferentes aspectos del espacio geográfico frente al mundo globalizado. Así en lo que se refiere a la vida cotidiana del ciudadano se requieren programas, acciones y formas de apropiación de los bienes de consumo en la vida de los ciudadanos. La problemática que envuelve el consumo de la ciudad forma parte de un tema transversal en la enseñanza escolar. El objetivo del trabajo es la aplicación de actividades pedagógicas que favorezcan la construcción de educandos críticos y conscientes sobre las formas de consumo en el cotidiano de nuestra sociedad en ese sentido orientado a la Educación Ambiental y Popular, se utilizarán recursos didácticos pedagógicos y prácticas educativas sobre el estudio del estudio consumo. El público objetivo de la investigación son los alumnos de la Escuela Municipal de Enseñanza Fundamental Euclides de la Cunha

\footnotetext{
${ }^{1}$ Cibele Stefanno Saldanha, graduada pela Universidade Federal de Santa Maria-UFSM, Mestranda pelo programa PPGGEO, Santa Maria, RS, Brasil. E-mail: cibele2012stefanno@gmai.com.

2 Sarana Martins Leivas, graduanda pela Universidade da Grande Dourados-UNIGRAN, Jaguarão,RS, Brasil. Email: sarana.martins.17@gmail.com.

3 Mauro Kumpfer Werlang, Prof. Dr.pela Universidade Federal de Santa Maria-UFSM, Santa Maria, RS, Brasil. E-mail: wermakwer@gmail.com.
} 
situada en el barrio Carolina, ciudad de Santa Maria, RS. Por lo tanto, el proceso de enseñanza-aprendizaje de los educandos y de los educadores en el hacer pedagógico fue elaborado asiduamente permitiendo la reflexión y la formación de ciudadanos que viven y construyen el cotidiano de su lugar y de su ciudad. Las temáticas propuestas en este proyecto referentes a la ciudad, ciudadanía, consumo sostenible que están siendo articuladas al estudio del lugar / barrio ya los métodos que fundamentan las prácticas adecuadas a aprendizajes, actitudes y comportamientos educativos en evaluación de los alumnos, ya que los resultados de las actividades fueron satisfactorios, los objetivos del proyecto se alcanzaron con éxito.

Palabras claves: Ciudadano; Conscientización; Enseñanza de la Geografía; Sostenibilidad..

\begin{abstract}
Consumption is a transversal theme that is relevant to all school subjects and must be developed in order to cover all life in the everyday life of learners. Geography addresses issues of consumption in different aspects of geographic space vis-a-vis the globalized world. Thus, in what concerns the daily life of the citizen, programs, actions and forms of appropriation of the consumer goods in the life of the citizens are required. The problem that involves the consumption of the city is part of a transversal theme in school education. The objective of the work is to apply pedagogical activities that favor the construction of critical and conscious students on the forms of consumption in the daily life of our society in this sense directed to Environmental and Popular Education, pedagogical didactic and practical-educational resources will be used on the study of the consumption. The target audience of the research are the students of the Municipal School of Elementary Education Euclides da Cunha located in the Carolina neighborhood, city of Santa Maria, RS. Therefore, the teaching-learning process of the learners and the educators in the pedagogical work was elaborated assiduously allowing the reflection and the formation of citizens who live and build the daily life of their place and their city. The themes proposed in this project related to the city, citizenship, sustainable consumption that are being articulated to the study of the place / neighborhood and to the methods that base the appropriate practices to the learning, attitudes and educational behaviors in evaluation of the students, since the results of the activities were satisfactory, the project objectives were successfully achieved.
\end{abstract}

Keywords: Citizen; Awareness; Teaching Geography; Sustainability.

\title{
1. Introdução
}

A temática desta pesquisa sobre o consumo na cidade envolve os alunos do $8^{\circ}$ ano e professores da Escola Municipal de Ensino Fundamental Euclides da Cunha em Santa Maria/RS, o objetivo da pesquisa é discutir e problematizar reflexões e práticas das ciências humanas, ambiente e fundamentos para uma Educação Ambiental Popular a relação natureza e sociedade na construção de perspectivas críticas na construção de conceitos e atitudes relevantes a formação da cidadania contextualizada bem como na relação local global. Tratase de um projeto que considera as teorias e práticas pedagógicas para o ensino de Geografia no que se refere às temáticas da cidade, da cidadania, e do meio ambiente, especialmente no que tange ao consumo enquanto atitude e hábitos na vida cotidiana.

Para isso, trata-se de relacionar aos conteúdos e a realidade nas atividades e discursos que envolvam a sociedade e a natureza; o local e o global. (CALLAI, 2000; CASTRIGIOVANNI, 2000). Todos os temas são inerentes a educação básica e devem cumprir com os objetivos e metas educando os alunos numa fase intelectual e de comportamento social muito importante a produção de valores e culturas. A inclusão dos temas transversais exige, portanto, uma tomada de posição diante de problemas fundamentais 
e urgentes da vida social, o que requer uma reflexão sobre o ensino e a aprendizagem de seus conteúdos: valores, procedimentos e concepções a eles relacionados.

O tema trabalho e consumo dos PCNs (BRASIL, 1998a) trazem uma proposta de discussão que envolve o comportamento da sociedade no mundo do consumo. O tema transversal trabalho e consumo deve-se ser adequado à formação de crianças e jovens para a sua inclusão no mundo do trabalho e do consumo de forma consciente na relação com os direitos e sua cidadania.

Um objeto utilizado no Brasil pode não possuir o mesmo significado e/ou utilidade em um país como a Índia, pois cada país possui suas peculiaridades, seus valores, suas tradições, que conduzirão os significados e os valores de troca atribuídos a este bem. Portanto, ao dizermos “que todo consumo é cultural, também estamos dizendo que todos os objetos são culturalmente significativos e que, na verdade, nenhum objeto pode ser simplesmente funcional" (SLATER, 2002).

Historicamente firmou-se o nome de Educação Popular no Brasil, e na maioria dos países latino-americanos, surge na passagem da década de 1950 para 1960. Segundo BRANDÃO (1986), alguns fatores foram decisivos para que fosse possível o seu nascimento: a subida ao poder, em vários países latino-americanos, de governos populistas; o engajamento de um considerável número de agentes provenientes dos setores médios da sociedade, pertencentes à intelectualidade estudantil, universitária, religiosa e militante, nas lutas populares como, por exemplo, no Brasil, a Ação Católica, os movimentos estudantis, dentre outros; e a ampliação de espaços dos movimentos populares existentes e o aparecimento de novas formas de organização popular, seriam alguns desses fatores que mereceriam destaque.

A Educação Popular nasceu como uma alternativa no campo educacional, político e pedagógico, gestada não somente a partir e com as camadas populares, mas por elas mesmas, frente às iniciativas educativas estatais "que não representavam ou até afetavam os interesses populares." (GADOTTI \& TORRES, 1994: 9)

\section{Desenvolvimento}

Nessa mesma perspectiva, foi dada a compreensão da organização espacial urbana pelos espaços ou lugares do consumo na cidade através de diferentes recursos didáticos e pelo trabalho de campo para identificação e percepção do espaço vivido pelo consumo com levantamento e registro de dados e informações significativas à aprendizagem.

Com os recursos didático-pedagógicos o projeto irá contribuir no processo de construção de conceitos e da compreensão do verdadeiro significado de cidade e de cidadania, 
pois a "educação na cidade" (FREIRE, 1991) é um fato que possui relevância e se constitui no caminho para a formação dos cidadãos.

As atividades didático-pedagógicas previstas para este projeto foram organizadas em oficinas pedagógicas:

\subsection{Oficina Pedagógica I - Diagnóstico dos educandos quanto ao tema proposto: “O consumo e o consumidor consciente"}

Primeiramente fomos até escola, onde foi realizada uma apresentação aos educandos e a direção da escola do projeto e de seus objetivos, sendo feita a concessão para que o projeto pudesse ser desenvolvido. A segunda etapa foi aplicação do um questionário o qual contou com 10 questões relacionadas ao consumo pessoal de cada educando.

\subsection{Oficina Pedagógica II - Seleção dos produtos de consumo}

Aos educandos foram disponibilizados encartes e folders de propagandas de produtos de consumo do tipo não perecíveis e dois envelopes para serem identificados com o nome e idade, e uma tesoura. Diante do material distribuído para cada aluno, a atividade se desenvolveu em duas partes:

$\mathbf{1}^{\text {a }}$ Parte: os alunos receberam encartes de propagandas de produtos de consumo de diversas lojas do comércio da cidade de Santa Maria. Diante do material, eles escolheram figuras de produtos de consumo que consideraram necessários para o dia-a-dia do consumidor, recortaram e colocaram dentro do envelope Número 1.

$2^{\text {a }}$ Parte: Diante dos encartes de propaganda, os educando escolheram os produtos de consumo que consideraram não-necessários, mas que são do desejo deles. Após os recortes, as figuras foram colocadas dentro do envelope Número 2.

O material foi recolhido para análise, segundo a metodologia de amostragem aleatória, com o objetivo de compreender quais foram os objetos de consumo escolhidos pelos educandos. Optou-se em classificar os objetos que chamaremos de produtos de consumo. Diante de cada envelope, os de $\mathrm{N}^{\mathbf{0}} 1$ e os de $\mathrm{N}^{\mathbf{0}} 2$, identificados pelos educandos com os produtos de consumo necessários e os produtos de consumo não-necessários, o quadro 1 considera os seguintes setores: 
Quadro 1- Classificação dos produtos por setores.

\begin{tabular}{|l} 
Quadro 1- Classificação dos produtos por setores. \\
\hline a) Cosméticos \\
b) Brinquedos \\
c) Eletrônicos (drones, aparelhos de som, TV, rádio, DVD) \\
d) Celulares \\
e) Computadores \\
f) Cozinha (louças, talheres, panelas) \\
g) Roupas de cama \\
h) Automóveis \\
i) Vestuário/calçados \\
j) Eletrodomésticos \\
k) Bicicletas \\
l) Motocicletas \\
\end{tabular}

Fonte: As autoras.

A partir da concessão da direção escolar para execução do projeto do curso de Geografia Licenciatura da Universidade Federal de Santa Maria o início das atividades ocorreu com uma breve conversa sobre a apresentação do projeto aos alunos, sujeitos da pesquisa e a direção da Escola Euclides da Cunha. O projeto iniciou com a apresentação das temáticas das oficinas pedagógicas que seriam trabalhadas e seus objetivos, inicialmente foram aplicados questionários com dez questões para cada educando referentes aos assuntos consumo e o consumidor consciente fazendo uma breve análise como os educandos entendem na temática que posteriormente foram trabalhados.

Em seguida foram distribuídos para cada educando uma pasta contendo dois envelopes com a seguinte referência: envelope 1 produtos necessários e envelope 2 produtos de desejo, as pastas foram identificada pelos alunos com nome, ano e idade. A preparação da atividade foi pela disposição, em mesas da sala de aula, de folhetos de propaganda sobre diversos tipos de produtos de consumo distribuídos pelo comércio da cidade de Santa Maria, RS, como: imóveis, farmácias, confecções, lojas de departamentos, entre outras.

A atividade se desenvolveu dizendo-se aos alunos que individualmente, procurassem nos folhetos de propaganda, as mercadorias que eles comprariam para o seu consumo diário, ou seja, necessário, após esta etapa realizada, os educandos realizaram a outra parte da oficina que foi selecionar os produtos de desejo. Após a escolha dos recortes dos produtos escolhidas os educandos colocaram separadamente os produtos nos envelopes e lacraram para não os misturar, e posteriormente colocaram dentro das pastas. A Figura 1 mostra os alunos da escola realizando a oficina cujo tema foi a seleção dos produtos necessários e produtos de desejo. 
RELACult - Revista Latino-Americana de Estudos em Cultura e Sociedade

Revista Latinoamericana de Estudios en Cultura y Sociedad | Latin American Journal of Studies in Culture and Society V. 04, ed. especial, fev., 2018, artigo no 706 | relacult.claec.org | e-ISSN: 2525-7870

FIGURA 1-Alunos realizando a primeira oficina pedagógica E.M.E.F Euclides da Cunha, Santa Maria, RS.

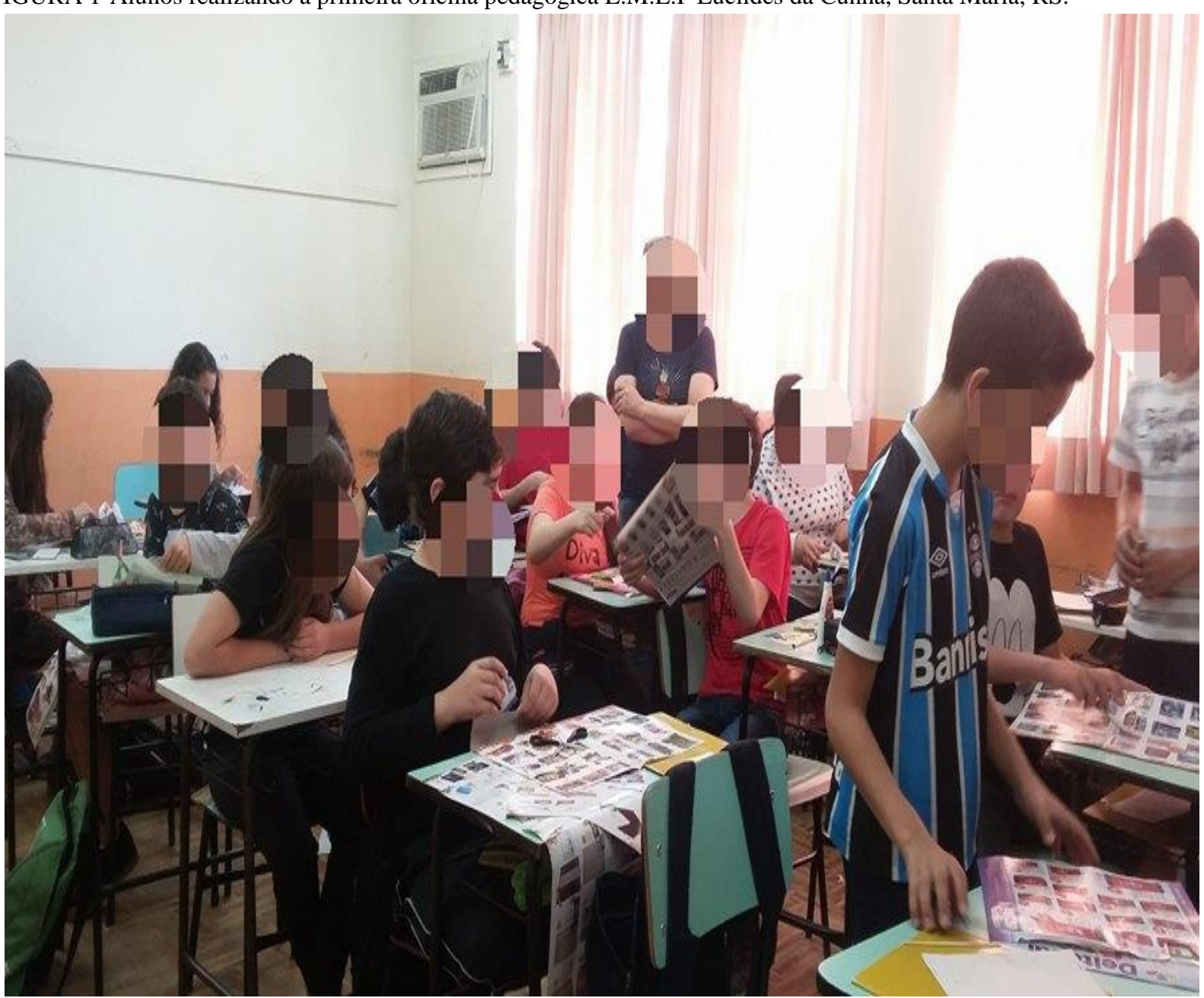

Fonte- Saldanha,C.S.

Tabela 1- Envelope ${ }^{\circ} 1$, produtos necessários.

\begin{tabular}{|c|c|c|}
\hline Setores de Consumo & Frequência & \% \\
\hline a) Cosméticos & 3 & - \\
\hline b) Brinquedos & - & 78,8 \\
\hline c) Eletrônicos & 30 & 6,5 \\
\hline d) smartphone & 25 & 3,1 \\
\hline e) Computadores e notebooks & 12 & 5,5 \\
\hline f) Cozinha & 21 & 1,0 \\
\hline g) Roupas de Cama & 4 & - \\
\hline h) Automóveis & - & 6,3 \\
\hline i) Vestuário/Calçados & 24 & 3,4 \\
\hline j) Acessórios & 13 & 25,7 \\
\hline k) Eletrodomésticos & 98 & 3,1 \\
\hline 1) Bicicletas & 12 & 1,0 \\
\hline m) Motocicletas & 4 & 18,1 \\
\hline n) Móveis & 69 & 15 \\
\hline p) Produtos Farmacêuticos & 57 & 2,1 \\
\hline p) Outros & 8 & $100 \%$ \\
\hline Total & 380 & \\
\hline
\end{tabular}

Fonte: Trabalho de campo, 2017, Turma 82

Podemos observar através da tabela os produtos por setores, a freqüência que apareceu cada produto e sua porcentagem, a primeira tabela representa o envelope de $n^{\circ} 1$ o qual foram 
selecionados os produtos diários (necessário para o dia-dia), os produtos selecionados totalizaram 380. O setor dos eletrodomésticos predominou nas escolhas dos educandos com porcentagem de $25,7 \%$, os produtos que mais se destacaram foram: geladeira, microondas, fornos, máquina de lavar roupa, batedeira, liquidificador entre outros.

Em $2^{\circ}$ lugar na ordem de preferência foram os móveis com uma porcentagem de $18,1 \%$, os produtos que mais aparecem foram: cama, sofá, estantes, mesas, pia e armários. Em $3^{\circ}$ lugar o setor que se destacou foi o farmacêutico com $15 \%$, os produtos com maiores índices foram os produtos de higiene como: sabonetes, shampoo, creme dental, escova de dente, desodorantes, barbeadores, remédios entre outros. Desta forma, podemos compreender que educandos tem uma ampla consciência ambiental colocando os eletrônicos em $4^{\circ}$ lugar na ordem de produtos necessário.

Tabela 2 - envelope $\mathrm{n}^{\circ} 2$ - Produtos de desejo.

\begin{tabular}{|c|c|c|}
\hline Setores de Consumo & Frequência & $\%$ \\
\hline a) Cosméticos & - & - \\
\hline b) Brinquedos & 38 & 19,3 \\
\hline c) Eletrônicos & 32 & 16,3 \\
\hline d) Smartphones & 25 & 5,7 \\
\hline $\begin{array}{c}\text { e) Computadores } \\
\text { notebooks }\end{array}$ & 11 & - \\
\hline f) Cozinha & - & - \\
\hline g) Roupas de Cama & - & 1,5 \\
\hline h) Automóveis & 3 & 16,3 \\
\hline i) Vestuário/Calçados & 32 & 1,0 \\
\hline j) Acessórios & 2 & 11,2 \\
\hline k) Eletrodomésticos & 22 & 4,0 \\
\hline 1) Bicicletas & 8 & 0,51 \\
\hline m) Motocicletas & 1 & 5,1 \\
\hline n) Móveis & 10 & - \\
\hline o) Produtos Farmacêuticos & - & 6,1 \\
\hline p) Outros & 12 & $100 \%$ \\
\hline Total & 196 & . \\
\hline Fon & & \\
\hline
\end{tabular}

Fonte: Trabalho de campo, 2017, Turma 82 da E.M.E.F. Euclides da Cunha.

Já os recortes do envelope de $n^{\circ} 2$ os artigos de desejo totalizaram 196 produtos, os setores que se destacaram foram os brinquedos com maior índice de preferência, com porcentagem 19,3\%, entre eles os jogos como Xbox, vídeo game, quebra-cabeças etc.

Seguindo o raciocínio dos produtos mais desejados em $2^{\circ}$ lugar aparecem os eletrônicos assim como o setor de vestuário, pois ambos tiveram uma porcentagem de 16,3\% de recortes. Os educandos do gênero masculino predominaram os eletrônicos entre eles os DVDs, drones, aparelhos de som, rádio entre outros, já o vestuário destacou-se pela "procura" dos educandos do gênero feminino por questões da faixa etária, podemos compreender ainda 
a os produtos de consumo com relação no que tange ao consumismo motivado pela mídia em nossa sociedade. E em $3^{\circ}$ lugar aparece o setor dos smartphones fazendo um total de 12,7\%.

A partir do estudo das tabelas podemos compreender que os educandos realizaram escolhas com diferenças consideráveis, pois na tabela de $\mathrm{n}^{\circ} 1$ o setor dos brinquedos não aparece nenhum utensílio do setor infantil visto que eram produtos necessários, já na tabela $\mathrm{n}^{\circ}$ 2 o setor dos brinquedos teve maior índice de preferência tanto por parte dos educandos do gênero masculino e do gênero feminino. Dessa forma os educandos realizaram a oficina proposta com bom discernimento na hora de escolher os produtos, sendo consumidores responsáveis.

\section{Conclusões}

Diante dos dados obtidos nessa primeira etapa, não afere-se considerações finais como conclusivas, pois se trata de um momento investigativo, o qual fornece dados e informações para diagnosticar e seguir na pesquisa teórico-metodológica para explicar hábitos e desejos de consumo de nossa sociedade, em especial de uma turma de jovens educandos.

A expectativa do projeto prevê ações e práticas pedagógicas aos professores e aos educandos afirmando o compromisso da escola com a construção e apropriação do conhecimento científico com reflexo na sociedade como um todo. O projeto teve como objetivo a conscientização e sensibilizar os alunos e professores de consumir consciente. Trabalhar com os educandos formação da cidadania para a vida urbana foram alguns dos eixos de preocupação condutor das reflexões apresentado neste trabalho.

Portanto, a proposta apresentada e desenvolvida pretendeu e pretende despertar a construir o conhecimento do educando e a vinculá-lo às experiências vividas com práticas diária para promover um consumo consciente, nos pequenos hábitos do dia a dia. É um desafio que culmina no objetivo maior da educação ambiental popular que é formar cidadãos ativos e comprometidos.

\section{Referências}

AKATU. Consumidor, o poder da consciência. São Paulo: Instituto Akatu, 2002.

BRASIL. Secretaria de Educação Fundamental. Parâmetros curriculares nacionais: terceiro e quarto ciclos, apresentação dos temas transversais. Brasília : MEC/SEF, 1998a.

BRASIL, Secretaria de Educação e Ensino Fundamental. Parâmetros Curriculares

Nacionais: Geografia. Brasília: MEC/SEF, 1998 b. 
BRANDÃO, Carlos Rodrigues. A questão política da Educação Popular. 2 ed. São Paulo: Brasiliense, 1980. 200 p.

Educação Popular.3 ed. São Paulo: Brasiliense, 1986. 88 p.

CALLAI, H. C. Estudar o lugar para compreender o mundo. In: CASTROGIOVANI, A. C. (Org.) Ensino de Geografia: Práticas e textualizações no cotidiano. Porto Alegre: Ed. Mediação, 2000.

CASTROGIOVANI, A. C.Ensino de Geografia:Práticas e textualizações no cotidiano. Porto Alegre: Ed. Mediação, 2000.

CAVALCANTI, L. S. A geografia escolar e a cidade: ensaios sobre o ensino de geografia para a vida urbana cotidiana. Campinas: Papirus, 2008.

FREIRE, P. A educação na cidade. São Paulo: Cortez Editora, 1991.

GADOTTI, Moacir; TORRES, Carlos Alberto. Poder e desejo: a educação popular como modelo teórico e como prática social. In: latinoamericana. São Paulo: Cortez, 1994. pp. 07-12. (orgs.). Educação popular: utopia

LEITE, P. R. Logística reversa:meio ambiente e competitividade. 2. ed. São Paulo: Pearson Prentice Hall, 2009.

SANTOS. M. O Espaço do Cidadão. São Paulo: Nobel, 1987.

MARX, Karl. Para a crítica da economia política. São Paulo: Abril Cultural, 1982. p. 9.

SLATER, Don. Cultura do consumo \& modernidade. Tradução de Dinah de Abreu Azevedo. São Paulo: Nobel, 2002 